\author{
SERIES 'PROTEOLYTIC ENZYMES AND AIRWAY DISEASES' \\ Edited by J.A. Nadel and R.A. Stockley \\ Number 3 in this Series
}

\title{
Role of neutrophil elastase in hypersecretion in asthma
}

\author{
J.A. Nadel, K. Takeyama, C. Agustí
}

\begin{abstract}
Role of neutrophil elastase in hypersecretion in asthma. J.A. Nadel, K. Takeyama, C. Agustí. CCES Journals Ltd 1999

ABSTRACT: Goblet cell (GC) hyperplasia and mucous plugging are common in patients with acute asthma. These patients also show neutrophil recruitment into the airways. Neutrophils contain elastase, a potent secretagogue in airways. Therefore, it was reasoned that neutrophil recruitment, by releasing elastase, could result in GC hypersecretion. When neutrophil chemoattractants were instilled in the airways of guinea-pigs, time-dependent neutrophil recruitment and GC degranulation occurred. An inhibitor of leukocyte infiltration (NP15669) prevented both responses, implicating neutrophils. An inhibitor of neutrophil elastase (ICI 200,355) abolished GC degranulation, implicating elastase. Further studies implicate movement of elastase from cytoplasmic granules to the neutrophil surface, and they suggest a role for adhesion molecules on neutrophils and on GCs in neutrophil-dependent GC degranulation. Similarly, instillation of ovalbumin (OVA) into airways of OVA-sensitized guinea-pigs caused early recruitment of neutrophils and GC degranulation. GC degranulation was prevented by pretreatment with NP15669 or ICI 200,355. These results implicate neutrophil release of elastase in allergen-induced hypersecretion. The results suggest a mechanism for the mucous plugging that occurs in acute asthma; prevention of neutrophil recruitment, prevention of neutrophil-GC adhesion, or inhibition of elastase activity could provide effective therapy for this serious pathophysiological abnormality.

Eur Respir J 1999; 13: 190-196.
\end{abstract}

Cardiovascular Research Institute and Dept of Medicine, University of California San Francisco, San Francisco, California, USA.

Correspondence: J.A. Nadel

Cardiovascular Research Institute Box 0130

University of California San Francisco

San Francisco, CA 94143-0130

USA

Fax: 14154762283

Keywords: Airways

CD11b/CD18

intercellular adhesion molecule-1 neutrophil chemoattractants secretagogue

Received: September 201998 Accepted after revision October 51998

Supported in part by the National Institutes of Health Program Project Grant HL24136
Hypersecretion is generally considered to be a major cause of symptoms in chronic bronchitis $[1,2]$, bronchiectasis [3], and cystic fibrosis [4]. Hypersecretion is a more neglected component of asthma, but airway hypersecretion also plays a significant role in its pathogenesis, especially in acute asthma. Post mortem studies reported mucous obstruction in small airways [5], and subsequent studies have reported that goblet cell (GC) hyperplasia and mucous plugging are important findings in patients who die of acute asthma $[6,7]$.

In healthy subjects [8] and in pathogen-free animals [9], airways generally contain few GCs, but airways of asthmatics and of individuals with other hypersecretory diseases airways show GC hyperplasia $[1-4,6,7]$. Thus, GC hypersecretion is presumed to be an important factor in hypersecretory diseases, especially in peripheral airways where prolific GCs could easily cause plugging.

\section{Goblet cell hypersecretion}

GC hypersecretion involves two separate processes: 1) GC metaplasia; and 2) GC degranulation. This article focuses on neutrophil-dependent GC degranulation. The mechanisms of hypersecretion are poorly understood, and there is no specific therapy. In chronic asthma, eosinophilic infiltrates predominate in airways, but acute, severe asthma is often associated with neutrophilic infiltration $[10,11]$. In fatal attacks of short duration, neutrophils were reported to be predominant [12]. In early status asthmaticus, neutrophil infiltration is common [13].

Neutrophil elastase is a potent secretagogue in airway GCs $[14,15]$ and in airway submucosal glands [16] in various species, including humans [17] and provides a possible mechanism for neutrophil-dependent hypersecretion. Delivery of antigen into airways in allergic humans and in sensitized animals results in leukocyte recruitment. In the early phase, recruitment is mainly neutrophilic [9, 18-21]. It was reasoned that neutrophil recruitment, by releasing elastase, could cause GC degranulation. To examine this hypothesis, two series of experiments were performed in guinea-pigs in vivo, evaluating GC degranulation in the airways. Firstly, chemoattractants (interleukin (IL)8 and $N$-formyl-leucyl-methionyl phenylalanine (fMLP)) were instilled into the trachea; in the second series of studies, ovalbumin (OVA) was instilled in the airways of sensitized animals. Neutrophil chemoattractants and antigen caused

Previous articles in this series: No. 1: P.S. Hiemstra, S. Van Wetering, J. Stolk. Neutrophil serine proteinases and defensins in chronic obstructive pulmonary disease: effects on pulmonary epithelium. Eur Respir J 1998; 12: 1200-1208. No. 2: G.U. Di Maria, S. Bellofiore, P. Geppetti. Regulation of airway neurogenic inflammation by neutral endopeptidase. Eur Respir J 1998; 12: 1454-1462. 
GC degranulation and neutrophil recruitment. The results indicate that chemoattractants cause neutrophil-dependent GC degranulation by adhesive interactions between neutrophils and GCs, resulting in elastase "release". Furthermore, the results implicate neutrophil elastase in allergen-induced $\mathrm{GC}$ degranulation. The results are reported in detail elsewhere $[15,22]$.

\section{Methods}

Methods of neutrophil-dependent GC degranulation are described in detail elsewhere [15] and will only be described briefly.

In vivo studies

Male Dunkin-Hartley outbred guinea-pigs (400-600 g; Simonsen Laboratories, Gilroy, CA, USA) were anaesthetized with pentobarbital sodium $\left(35 \mathrm{mg} \cdot \mathrm{kg}^{-1}\right.$, i.p.; Anthony Products, Arcadia, CA, USA). Drugs were delivered into the trachea via a 22 gauge angiocath catheter (Becton Dickinson, Sandy, UT, USA). At preselected times, the animals were perfused with $1 \%$ paraformaldehyde, the trachea was removed and placed in 4\% paraformaldehyde $(24 \mathrm{~h})$, and then the trachea was cut and embedded in JB-4 plus monomer solution (Polyscience, Warrington, PA, USA). Sections $(4 \mu \mathrm{m})$ were placed on a slide, stained with 3, 3'-diaminobenzidine (Sigma, St. Louis, MO, USA) to visualize migrated neutrophils. Neutrophils seen as myeloperoxidase-positive blue cytoplasmic cells were counted in 20 consecutive high-power fields of the epithelial layer. Slides were stained with Alcian blue/periodic acid-Schiff (PAS) and counterstained with haematoxylin and observed at $\times 400$ magnification. IL-8 and fMLP were chosen to stimulate neutrophil migration, and the trachea was removed (1-4 h) after injection.

\section{Quantification of goblet cell degranulation}

The volume density of Alcian blue/PAS-stained mucosubstances on the mucosal surface epithelium was determined using a semiautomatic imaging system.

\section{In vitro studies}

The trachea was removed and cut into segments, bathed in Dulbecco's modified Eagle's medium (DMEM)-Hams F-12 medium containing HEPES buffer $(25 \mathrm{mM})$ and incubated at $37^{\circ} \mathrm{C}$ in a $5 \% \mathrm{CO}_{2}$ water-jacketed incubator (Forma Scientific, Marietta, OH, USA). After the in vitro studies, the tracheal segments were prepared similarly to the in vivo studies.

\section{Isolation of neutrophils}

Because of the difficulty of obtaining sufficient guineapig neutrophils, human neutrophils were used in most experiments, purifying them from normal peripheral blood, as described elsewhere [15].

\section{Sensitization and intratracheal challenge with OVA}

Guinea-pigs were sensitized with OVA, $2.5 \mathrm{mg}$, i.p.; (grade V; Sigma), complexed with $50 \mathrm{mg}$ alum in $0.5 \mathrm{~mL}$ $\mathrm{NaCl}(0.9 \%)$ on days 0 and 10 . Intratracheal challenge with OVA was performed between days 20 and 22. The animals received an injection of pyrilamine maleate $\left(10 \mathrm{mg} \cdot \mathrm{kg}^{-1}\right.$, i.p.) $30 \mathrm{~min}$ before OVA challenge to prevent fatal anaphylactic shock. A $2 \%$ OVA solution in $150 \mu \mathrm{L}$ saline was instilled.

\section{Results}

Effect of neutrophil chemoattractants on GC degranulation in vivo

Instillation of neutrophil chemoattractants fMLP and IL8 (each at $10^{-7} \mathrm{M}, 100 \mu \mathrm{L}$ ) intratracheally in guinea-pigs $(\mathrm{n}=5$ animals per group) caused neutrophil recruitment (fig. 1a) and GC degranulation (fig. 1b) in a time-dependent fashion. Neutrophil recruitment and GC degranulation
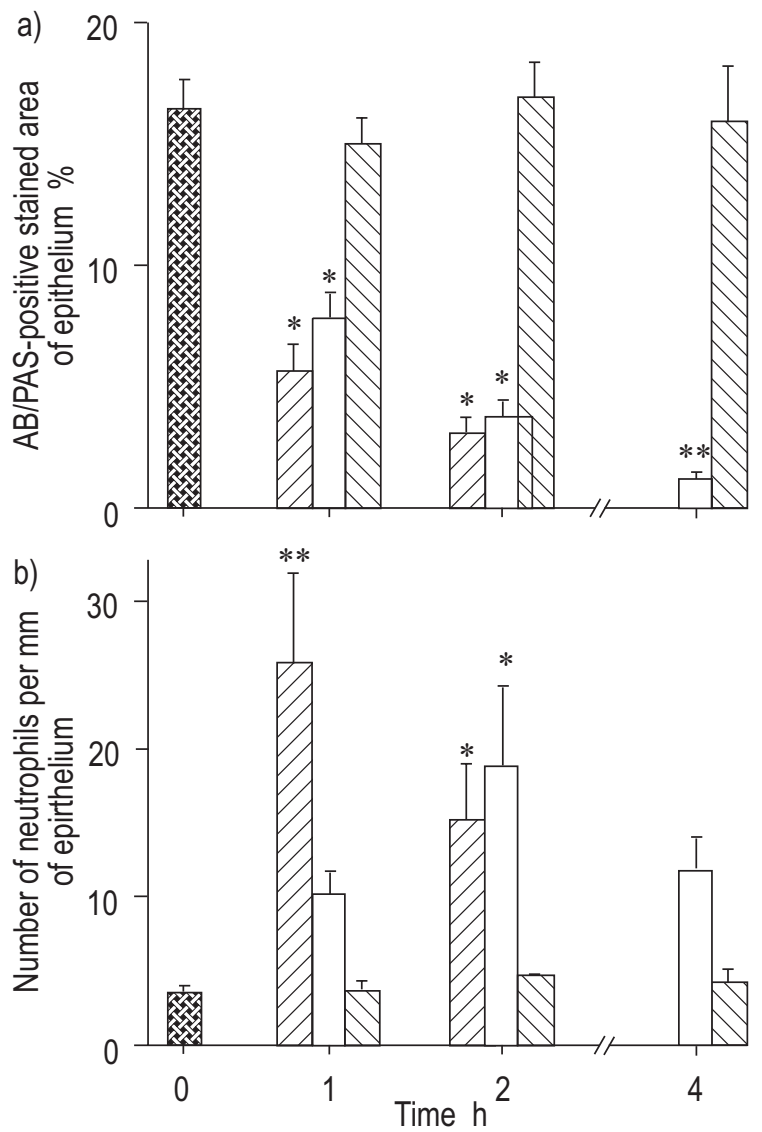

Fig. 1. - In vivo time course of effect of intratracheal injection of $\mathrm{N}$ formyl-leucyl-methionyl-phenylalanine ( $\left.f \mathrm{MLP} ; 100 \mu \mathrm{L}, 10^{-7} \mathrm{M}\right)$ and of interleukin (IL)-8 $\left(100 \mu \mathrm{L}, 10^{-7} \mathrm{M}\right)$ on a) goblet-cell degranulation (expressed as a percentage of the area of epithelium stained with Alcian blue (AB) periodic acid-Schiff (PAS) and on b) neutrophil recruitment in guinea-pig trachea. $\mathrm{x}$ : control (animals euthanized immediately, without stimulation); $\square$ : intratracheal injection of fMLP $\left(100 \mu \mathrm{L}, 10^{-7}\right.$ M); $\square$ : intratracheal injection of IL-8 $\left(100 \mu \mathrm{L}, 10^{-7} \mathrm{M}\right) ; \nabla$ : intratracheal injection of sterile phosphate-buffered saline (PBS; $100 \mu \mathrm{L}) . n=5$ animals for each group. Responses are expressed as mean \pm SEM. *: $\mathrm{p}<0.05$; $^{* *}: \mathrm{p}<0.01$, significantly different from control values. 
were dose-dependent. Pretreatment with NP-15669 (10 $\mathrm{mg} \cdot \mathrm{kg}^{-1}, i . v$.), a molecule that prevents neutrophil migration [21], inhibited both neutrophil recruitment and GC degranulation completely $(\mathrm{p}<0.01)$. From these studies, it was concluded that IL-8-induced GC degranulation is neutrophil -dependent.

Pretreatment with ICI 200,355 (700 $\mu \mathrm{g} \cdot \mathrm{kg}^{-1} i . v$; ; an inhibitor of neutrophil elastase) prevented IL-8-induced GC degranulation, implicating neutrophil elastase in neutrophil-dependent GC degranulation. Purified neutrophil elastase is a potent secretagogue in airway submucosal glands [16] and in GCs [14, 16] of various species [17], but when neutrophils are incubated with a neutrophil chemoattractant in a test tube, elastase is not normally released into the supernatant [23], indicating that elastase is not easily exocytosed from neutrophils stimulated by chemoattractants. Therefore, to discover how neutrophil elastase becomes available to degranulate goblet cells, in vitro studies were performed.

\section{In vitro studies}

Incubation of guinea-pig tracheal segments $(\mathrm{n}=4$ animals per group) for $1 \mathrm{~h}$ with IL-8 $\left(10^{-7} \mathrm{M}\right)$, fMLP $\left(10^{-8} \mathrm{M}\right)$, or with neutrophils $\left(10^{6}\right.$ cells $\left.\cdot \mathrm{mL}^{-1}\right)$ alone was without effect. However, incubation of tracheal segments with chemoattractant plus neutrophils together resulted in profound GC degranulation (fig. 2).

To determine whether GC degranulation was due to exocytosis of elastase and subsequent diffusion to the GC, or whether elastase remaining on the surface of neutrophils was responsible for degranulation, neutrophils were incubated with chemoattractants for $1 \mathrm{~h}$. Then the neutrophils were harvested and washed with phosphate-buffered saline

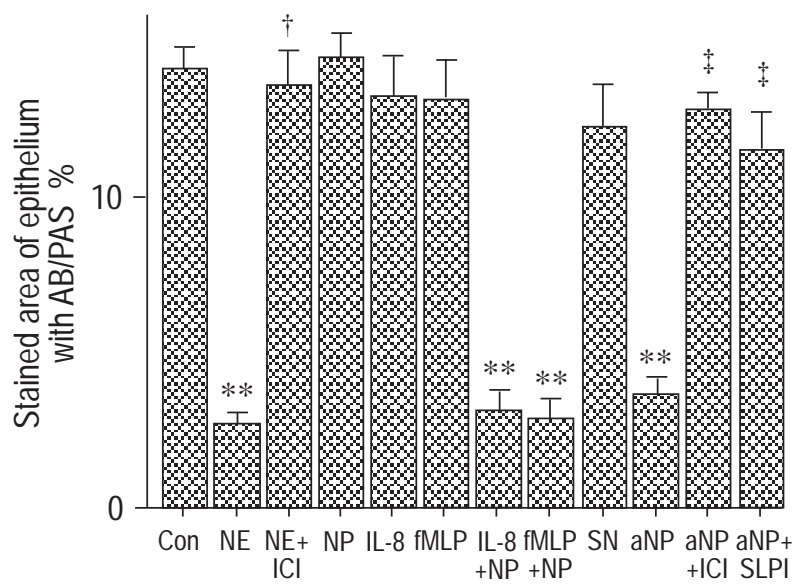

Fig. 2. - In vitro effect of neutrophils (NP) and of neutrophil chemoattractants on goblet cell degranulation (expressed as a percentage of the area of epithelium stained with Alcian blue (AB)/periodic acid-Schiff (PAS) in guinea-pig trachea. Various conditions examined include purified neutrophil elastase (NE; $10^{-7} \mathrm{M}$, used as positive control (Con)), $\mathrm{NE}\left(10^{6}\right.$ cells $\left.\cdot \mathrm{mL}^{-1}\right)$ alone, interleukin-8 (IL-8; $\left.10^{-7} \mathrm{M}\right)$ alone, $N$ formyl-leucyl-methionyl-phenylalanine (fMLP; $10^{-8} \mathrm{M}$ ) alone, NP plus chemo-attractant, NP "activated" (aNP) by IL-8 or their supernatant $(\mathrm{SN})$. The effects of the NE inhibitors, ICI 200,355 (ICI; $10^{-5} \mathrm{M}$ ) and secretory leukocyte protease inhibitor (SLPI; $10^{-5} \mathrm{M}$ ) were also studied. Responses are expressed as meansEM; $\mathrm{n}=4$ for each group. $* *: \mathrm{p}<0.01$, significantly different from control values. ${ }^{\dagger}: \mathrm{p}<0.01$, significantly different from response to NE. $\star_{:}<<0.01$, significantly different from the response to aNP
(PBS) to avoid any further contamination with IL-8. The "activated" neutrophils caused GC degranulation, but the supernatant was without effect (fig. 2). Preincubation of the activated neutrophils with the elastase inhibitors ICI $200,355\left(10^{-5} \mathrm{M}\right)$ or secretory leukocyte proteinase inhibitor (SLPI; $10^{-5} \mathrm{M}$ ) prevented GC degranulation, indicating that elastase plays a role in the degranulation. These results suggest that elastase bound to neutrophils, and not elastase released into the free medium, causes GC degranulation. Therefore, the effect of neutrophil chemoattractants were studied on fibronectin-coated chamber slides to examine any possible translocation of elastase from the cytoplasm to the neutrophil surface.

\section{Immunocytochemical localization of neutrophil elastase}

Chemoattractants caused the surface expression of neutrophil elastase in a time-dependent manner. Adherent neutrophils incubated alone did not change shape and did not stain for elastase over a period of $45 \mathrm{~min}$. Neutrophil incubation with chemoattractants resulted in changes in neutrophil shape; surface staining of elastase was present at $5 \mathrm{~min}$ and was at a maximum at $15 \mathrm{~min}$. Surface staining was polarized, being stronger on one side of the neutrophils (fig. 3). These studies show that chemoattractants
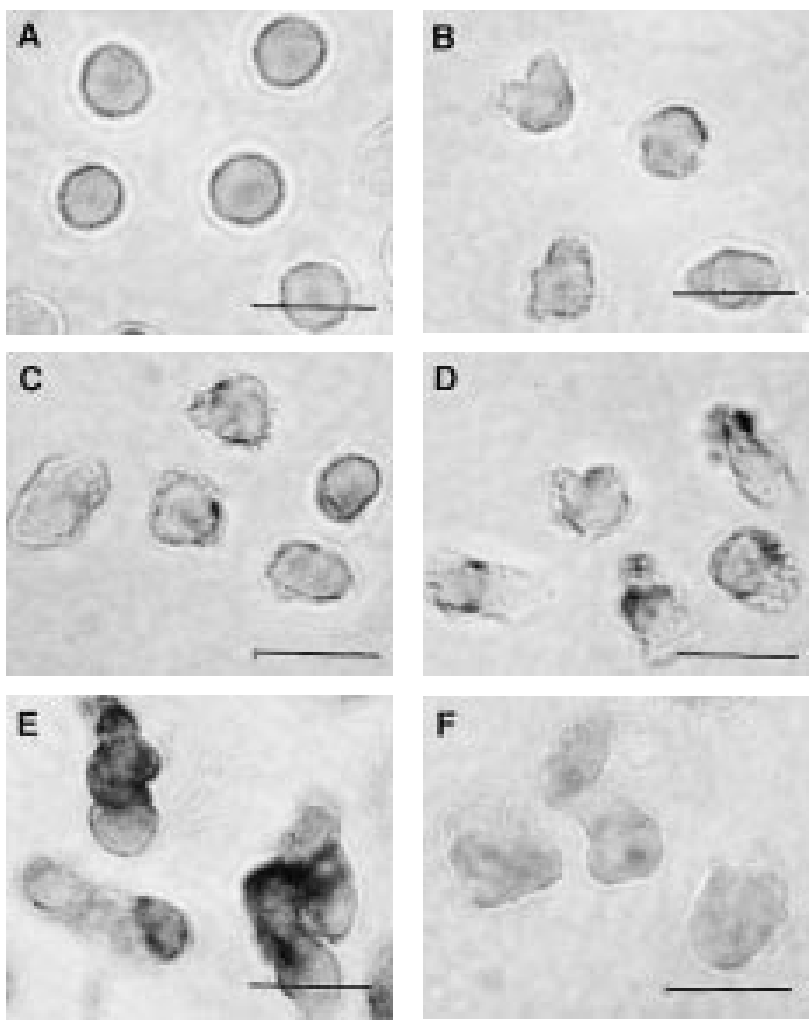

Fig. 3. - Time-course of the effect of $\mathrm{N}$-formyl-leucyl-methionylphenylalanine (fMLP) on the surface appearance of neutrophil elastase in isolated neutrophils on fibronectin-coated chamber slides. Isolated neutrophils were incubated under various conditions on fibronectincoated chamber slides. A: without fMLP; B: 2 min with fMLP $\left(10^{-8} \mathrm{M}\right)$; C: 5 min with fMLP $\left(10^{-8} \mathrm{M}\right)$; D: 10 min with fMLP $\left(10^{-8} \mathrm{M}\right)$; E and F: 15 min with fMLP $\left(10^{-8} \mathrm{M}\right)$. Cells were stained with a monoclonal mouse antihuman neutrophil elastase antibody (A-E) or with the antibody preabsorbed with a 100 -fold excess of the purified neutrophil elastase $(\mathrm{F})$. (Internal scale bars $=160 \mu \mathrm{m}$.) 
cause elastase to be expressed on the surface of neutrophils, where it is capable of interacting with tissue substrates (e.g. GCs).

To determine whether or not membrane-bound elastase is enzymatically active, the elastase activity of neutrophils was measured with an elastase-specific fluorogenic substrate (methoxysuccinyl-Ala-Ala-Pro-Val-7-amino-4-trifluoromethylcoumarin; $200 \mu \mathrm{M}$ in $0.1 \mathrm{M}$ HEPES buffer containing $0.15 \mathrm{M} \mathrm{NaCl}$ ) for $25 \mathrm{~min}$ at room temperature. When neutrophils were incubated for $30 \mathrm{~min}$ with a chemoattractant, cleavage of the substrate by catalytically active membrane-bound elastase increased strikingly (fig. 4). These studies are compatible with the results of a recent study describing the binding of elastase to the neutrophil plasma membrane [24]. The studies by OwEN et al. [25] showed the importance of surface-bound elastase and of the pericellular environment in determining the enzymatic activity of elastase in tissues.

Role of adhesion molecules in neutrophil-dependent $G C$ degranulation

Because elastase remains on the surface of stimulated neutrophils and is not secreted into the free medium, it was hypothesized that a close contact interaction between the surface of GCs and neutrophils is required for GC degranulation. Pretreatment of neutrophils with an antiCD11b or anti-CD18 antibody inhibited chemoattractantmediated GC degranulation. Similarly, preincubation of tracheal segments with an anti-intercellular adhesion molecule (ICAM)-1 antibody also prevented GC degranulation. These findings implicate adhesion molecules on neutrophils and GCs in neutrophil-dependent GC degranulation.

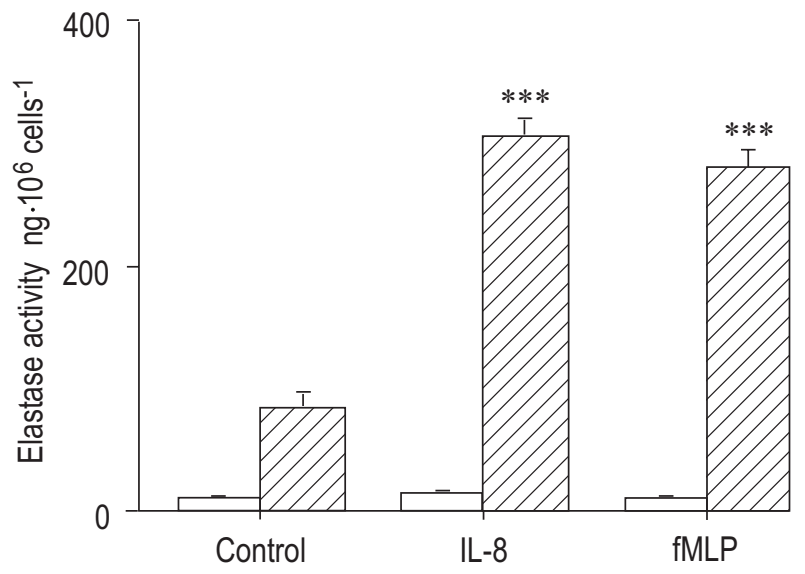

Fig. 4. - Effect of chemoattractants on catalytic activity of neutrophil elastase by methoxysuccinyl-Ala-Ala-Pro-Val-7-amino-4-trifluoromethyl coumarin (AFC). Neutrophils $\left(10^{6}\right.$ cells) were incubated with interleukin-8 (IL-8; $10^{-8} \mathrm{M}$ ) or with $N$-formyl-leucyl-methionylphenylalanine (fMLP; $10^{-8} \mathrm{M}$ ) for $30 \mathrm{~min}$ in a test tube. Cells were fixed with phosphate-buffered saline containing 3\% paraformaldehyde and $0.5 \%$ glutaraldehyde $(\mathrm{pH} 7.4)$. Elastase activity was measured in the supernatant $(\square)$ or on the surface of neutrophils $(\square)$ using AFC, a fluorogenic substrate that is specific for elastase. Data are expressed as elastase activity, ng $\cdot 10^{6}$ cells $^{-1}$. Responses are expressed as mean $\pm \mathrm{SEM}$; $\mathrm{n}=4$ for each group. $* * *: \mathrm{p}<0.001$, significantly different from control values.
Studies of human airways in vitro

Bronchial segments removed from four patients at the time of lung transplantation were selected because they contained GCs. The results were similar for guinea-pigs: incubation of bronchial segments with neutrophils plus IL8 led to marked GC degranulation, an effect that was inhibited by an anti-CD18 antibody (fig. 5). Effect of OVA challenge on GC degranulation in sens-
itized guinea-pigs

These studies are reported in detail elsewhere [22]. Intratracheal instillation of OVA $(2 \% ; 150 \mu \mathrm{L})$ caused a marked GC degranulation that was significant within $1 \mathrm{~h}$, persisted at $2 \mathrm{~h}$ and was associated with neutrophil recruitment into the tracheal epithelium. Pretreatment with NPC 15669 (10 $\mathrm{mg} \cdot \mathrm{kg}^{-1}$, i.v.), a drug that prevents leukocyte migration, inhibited both neutrophil recruitment and GC degranulation. Pretreatment with an elastase inhibitor, ICI $200,355\left(700 \mu \mathrm{g} \cdot \mathrm{kg}^{-1}\right.$, i.v. $)$, also inhibited GC degranulation, but neutrophil recruitment was unaffected. Pretreatment with an anti-ICAM antibody (150 $\mu \mathrm{g} \cdot \mathrm{kg}^{-1}$ i.v.) significantly inhibited neutrophil recruitment and GC degranulation. These results suggest that antigeninduced GC degranulation is neutrophil-dependent, and that it involves a process involving adhesive interactions between the GC and neutrophil elastase acting at the neutrophil surface.

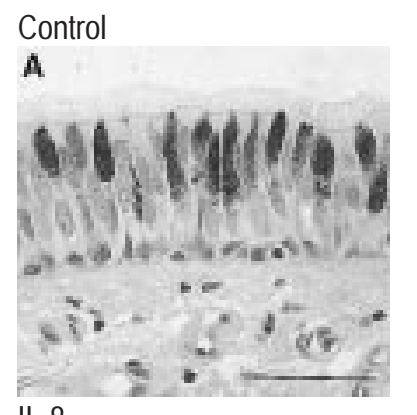

Neutrophils
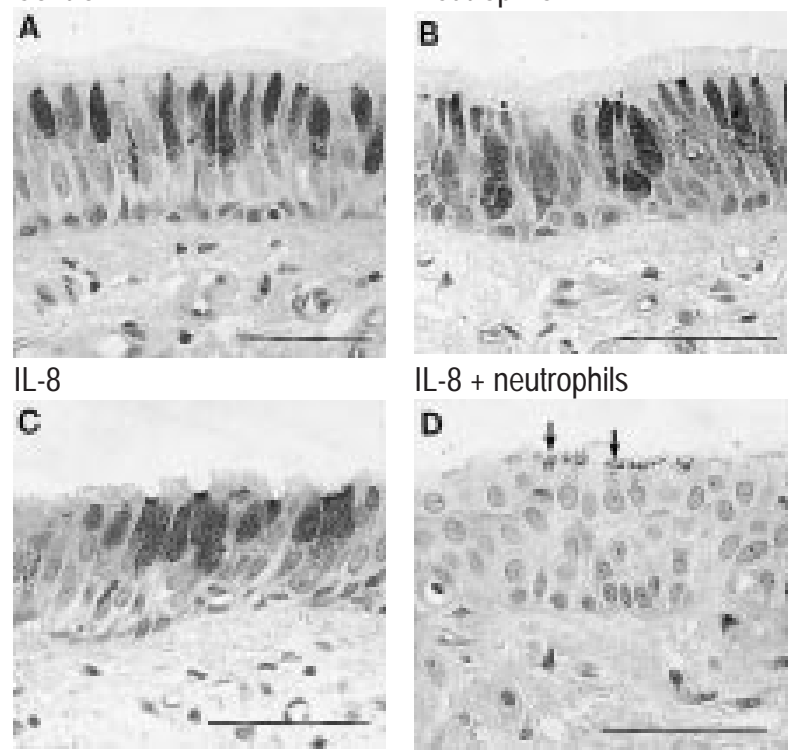

IL-8 + neutrophils

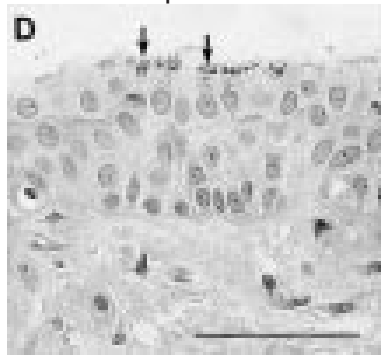

Fig. 5. - Photomicrographs of human bronchial epithelium removed from a patient with idiopathic pulmonary fibrosis at the time of lung transplantation and stained with Alcian blue/periodic acid-Schiff (PAS). In the unstimulated condition, Alcian Blue-staining cells are conspicuous in the bronchial epithelium (A). Bronchial segments that are incubated with neutrophils alone (B) or with interleukin (IL)- 8 alone (C) do not show degranulation. However, segments incubated with IL-8 plus neutrophils show profound goblet cell degranulation (D; arrows). (Internal scale bars $=50 \mu \mathrm{m}$.) 


\section{Discussion}

Purified neutrophil elastase is a potent secretagogue in airways [14-17], but when neutrophils are incubated with mediators that "activate" neutrophils in vitro, elastase is not normally released, so it is unclear whether or not intact neutrophils cause hypersecretion in vivo. Some effects of inflammatory cells have been shown to be due to intimate interactions between the inflammatory cell and tissue targets, and it was hypothesized that elastase could be released by a close contact interaction between neutrophils and GCs. Therefore, the effect of neutrophil chemoattractants on GC degranulation was studied in guinea-pigs in vivo. Instillation of neutrophil chemoattractants into the airways was shown to result in rapid neutrophil recruitment into the airway epithelium and GC degranulation. Inhibition of leukocyte motility (which inhibited neutrophil migration into the airways) prevented chemoattractant-induced GC degranulation, implicating neutrophils and their products in the response. Neutrophils contain three proteases capable of causing secretion: elastase, cathepsin G [16] and proteinase-3 [26, 27]. In the present studies, pretreatment with ICI 200,355, a selective inhibitor of elastase and proteinase-3 but not cathepsin G [28], prevented chemoattractant-induced GC degranulation. SLPI, an inhibitor of elastase and cathepsin $\mathrm{G}$ but not proteinase-3 [29], also prevented the GC degranulation. These findings implicate elastase in neutrophil-dependent GC degranulation.

To examine the mechanism of the elastase-induced effects, in vitro studies were performed. Neutrophils isolated from blood and incubated with tracheal tissue did not cause GC degranulation, but when the neutrophils were preincubated with chemoattractants and then incubated with airway epithelium, rapid and profound degranulation occurred, indicating that neutrophil activation was required for neutrophil-mediated GC degranulation.

Next, neutrophils were incubated with chemoattractants and the cells separated from the supernatant, and it was found that the neutrophils retained the ability to cause GC degranulation. It was concluded that elastase must have migrated from azurophilic granules in the cytoplasm, where it resides in resting neutrophils, to the neutrophil surface, where it is enzymatically active and available to tissue substrates (e.g. GCs).

When neutrophils are isolated and stained with an antibody, the antibody is too large a molecule to enter the cell, so only surface staining occurs. In the present study, resting neutrophils showed little surface staining, but when neutrophils were incubated with a chemoattractant, timedependent surface staining occurred, which was marked by $15 \mathrm{~min}$. These findings indicate that elastase activity in resting cells resides in the cytoplasm; during stimulation, surface expression of elastase occurs. These studies of surface elastase confirm the novel studies by OwEN et al. [24], who showed that in neutrophils incubated with chemoattractants, elastase moves to the surface and induces cleavage of elastase-specific substrates. The present studies implicate surface expression of elastase in the interaction with GCs.

Because elastase activity remained bound to the "activated" neutrophils, it was reasoned that a close interaction between neutrophils and GCs must occur to allow the elastase activity to signal GC degranulation. Adhesion molecules can be expressed on neutrophils (e.g. MAC-1) and on airway epithelial cells (e.g. ICAM-1). These molecules have been characterized most extensively for their adhesive properties, but they are also reported to be involved in signal transduction in cells, especially in inflammatory responses [30]. In the present studies, blocking antibodies on epithelial cells (anti-ICAM-1) or on neutrophils (anti-MAC-1) inhibited neutrophil chemoattractantinduced GC degranulation. The exact mechanism by which the adhesive interactions permit surface-bound elastase on neutrophils to gain access to GCs is unknown. Perhaps MAC-1/ICAM-1 interaction stimulates the production of a second messenger in the neutrophils. The second messenger could change the conformation of surface-bound elastase, making it more accessible to GCs.

Another unknown is the exact molecular mechanism of elastase-induced degranulation of secretory cells. Proteinases, including neutrophil elastase [16], mast cell chymase [31], and cathepsin G [16] are the most potent secretagogues identified to date. Receptor-coupled secretion by agonists such as histamine occurs via cyclic adenosine monophosphate (cAMP), protein kinase $\mathrm{C}$, and intracellular $\mathrm{Ca}^{2+}$ concentration-dependent pathways, but degranulation induced by elastase does not involve identified second messengers [32]. Elastase may activate degranulation directly, bypassing the signal transduction mechanisms necessary for receptor-mediated secretion.

What role could neutrophil-mediated hypersecretion play in disease? In chronic bronchitis [1, 2], bronchiectasis [3], and cystic fibrosis [4], where symptomatic hypersecretion is associated with neutrophil recruitment in the airways, the relevance is obvious. The relationship to asthma is more subtle! Chronic asthma is associated with eosinophilic infiltration of airways, especially in the submucosa. Because the half-life of eosinophils is measured in weeks (the half-life of neutrophils is days), it is assumed that inflammatory effects in asthma must be due, in large part, to eosinophils.

However, when neutrophils are recruited in the airways, they migrate from postcapillary venules located just below the epithelium. For example, in the present studies, airway recruitment of neutrophils by chemoattractants is seen in $<1 \mathrm{~h}$ and is at a maximum in $2 \mathrm{~h}$. Similarly, airway instillation of antigen stimulates neutrophil recruitment over a similar time period. During recruitment, neutrophils come in close contact with GCs, allowing a close contact interaction to occur. Thus, neutrophils travelling through the airway epithelium could play a major role in GC degranulation without prolonged residence in airway tissue.

An important question is what pathophysiological stimuli are most likely to promote neutrophil infiltration in airways in asthma? One can speculate on two possibilities: firstly, respiratory viruses induce the release of neutrophil chemoattractants from airway epithelial cells [33] and neutrophil infiltration, so viral infections could cause GC degranulation; and secondly, inhalation of antigens induces leukocytic infiltration characterized by early $(1-4 \mathrm{~h})$ neutrophil recruitment and later $(12-48 \mathrm{~h})$ eosnophil recruitment. Thus, inhalation of antigen could result in striking and rapid GC degranulation. Experimental models of asthma in rodents show that local delivery of antigen causes mucous plugging and leukocyte infiltration [34]; the present studies provide a mechanistic explanation for this effect. 
The role of GC degranulation in clinical asthma remains unknown, and the solution may not be simple for several reasons. GC degranulation is likely to have the most significant effects in small airways, where degranulation of large GCs could easily completely obstruct individual airways. Obstruction of peripheral airways is not sensitively detected by the usual tests of pulmonary function [35], so alternative methods must be used. Airway plugging leads to areas of poor (or absent) ventilation, and this could lead to hypoxaemia (low ventilation compared to perfusion). Thus, a decrease in oxygen saturation without a drop in forced expiratory volume could suggest that peripheral mucus plugging is occurring. Furthermore, it would be useful if methods could be developed to visualize obstructed small airways.

Another important issue is the asthmatic population in which GC degranulation is most likely to be important. Again, this is unknown, but several facts are helpful. The post mortem findings were compared in asthmatic patients who died of severe acute asthma, asthmatics who died without evidence of severe acute asthma, and control subjects who died of nonrespiratory disorders. Airways of severe acute asthmatics showed 30 -fold increases in GC area in peripheral airways with marked accumulation of mucus in airway lumens. However, in nonacute asthmatics, the GC areas and amounts of mucus in the lumens was small and not different from one another [7]. Similarly, SAETTA et al. [6] reported that asthmatics who died suddenly showed airway luminal occlusion with mucous plugs. These findings suggest that the morphological changes in acute, severe asthma differ from other asthmatics and that the risk factors in this population may be different.

One hypothesis is that susceptibility to mucous plugging of airways is determined by the existence and degree of goblet cell metaplasia that exists in the patient's peripheral airways. Thus, some patients may have massive overgrowth of peripheral airways by goblet cells, as seen in the airways of patients with mucous plugging who died of acute, severe asthma [7]. It is reasonable to assume that asthmatic individuals with marked goblet cell hyperplasia may be most at risk from stimuli (e.g. viral infections, inhalation of allergens) which may trigger goblet cell degranulation. An understanding of the mechanisms responsible for goblet cell growth and their prevention provides an important therapeutic strategy.

\section{References}

1. Snider GL, Faling U, Rennard SI. Chronic bronchitis and emphysema. In: Murray JF, Nadel JA, eds. Textbook of Respiratory Medicine. Philadelphia, PA, Saunders, 1994; pp. 1331-1397.

2. Stockley RA, Hill SL, Morrison HM, Starkie CM. Elastolytic activity of sputum and its relation to purulence and to lung function in patients with bronchiectasis. Thorax 1984; 39: 408-413.

3. Fahy JV, Schuster A, Ueki I, Boushey HA, Nadel JA. Mucus hypersecretion in bronchiectasis. The role of neutrophil proteases. Am Rev Respir Dis 1992; 146: 1430-1433.

4. Boat TF, Boucher RC. Cystic fibrosis. In: Murray JF, Nadel JA, eds. Textbook of Respiratory Medicine. Philadelphia, PA, Saunders, 1994; pp. 1418-1450.
5. Dunhill MS. The pathology of asthma with special reference to changes in the bronchial mucosa. J Clin Pathol 1960; 13: 27-33.

6. Saetta M, De Stefano A, Rosina C, Thiene G, Fabbri LM. Quantitative structural analysis of peripheral airways and arteries in sudden fatal asthma. Am Rev Respir Dis 1991; 143: $138-143$.

7. Aikawa T, Shimura S, Sasaki H, Ebina M, Takishima T. Marked goblet cell hyperplasia with mucus accumulation in the airways of patients who died of severe acute asthma attack. Chest 1992; 101: 916-921.

8. Dunhill MS, Massarella GR, Anderson JA. A comparison of the quantitative anatomy of the bronchi in normal subjects, in status asthmaticus, in chronic bronchitis and in emphysema. Thorax 1969; 24: 176-179.

9. Blyth DI, Pedrick MS, Savage TJ, Hessel EM, Fattah D. Lung inflammation and epithelial changes in a murine model of atopic asthma. Am J Respir Cell Mol Biol 1996; 14: 425-438.

10. Sur S, Crotty TB, Kephart GM. Sudden onset fatal asthma. A distinct entity with few eosinophils and relatively more neutrophils in the airway submucosa. Am Rev Respir Dis 1993; 48: 713-719.

11. Fahy JV, Kim KW, Liu J, Boushey HA. Prominent neutrophilic inflammation occurs in sputum from subjects with asthma exacerbation. J Allergy Clin Immunol 1995; 95: 843-852.

12. Carroll N, Carello S, Cooke C, James A. Airway structure and inflammatory cells in fatal attacks of asthma. Eur Respir J 1996; 9: 709-715.

13. Lamblin C, Gossett P, Tillie-Leblond I, et al. Bronchial neutrophilia in patients with noninfectious status asthmaticus. Am J Respir Crit Care Med 1998; 157: 394-402.

14. Breuer R, Christensen TG, Lucey EC, Stone PJ, Snider GL. An ultrastructural morphometric analysis of elastasetreated hamster bronchi shows discharge followed by progressive accumulation of secretory granules. Am Rev Respir Dis 1987; 136: 698-703.

15. Takeyama K, Agustí C, Ueki I, Lausier J, Nadel JA. Neutrophil-dependent goblet cell degranulation: role of membrane-bound elastase and adhesion molecules. $\mathrm{Am} \mathrm{J}$ Physiol 1998; 275 (Lung Cell Mol Physiol 19): L294302.

16. Sommerhoff CP, Nadel JA, Basbaum CB, Caughey GH. Neutrophil elastase and cathepsin G stimulate secretion from cultured bovine airway gland serous cells. J Clin Invest 1990; 85: 682-689.

17. Schuster A, Ueki I, Nadel JA. Neutrophil elastase stimulates tracheal submucosal gland secretion that is inhibited by ICI 200,355. Am J Physiol 1992; 262 (Lung Cell Mol Physiol 6): L86-L91.

18. O'Riordan T, Otero R, Mao Y, Lauredo I, Abraham WM. Elastase contributes to antigen-induced mucociliary dysfunction in ovine airways. Am J Respir Crit Care Med 1997; 155: 1522-1528.

19. Hutson PA, Church MK, Clay TP, Miller P, Holgate ST. Early and late-phase bronchoconstriction after allergen challenge of nonanesthetized guinea pigs. Am Rev Respir Dis 1988; 137: 548-557.

20. Church MK, Hutson PA, Holgate ST. Nedocromil sodium blocks the early and late phases of allergen challenge in a guinea pig model of asthma. J Allergy Clin Immunol 1993; 92: 177-182.

21. Kaneko T, Jorens PG, Richman-Eisentat Y, Dazin PF, Nadel JA. Leumedin NPC 15669 inhibits antigen-induced recruitment of inflammatory cells into the canine airways. Am J Physiol 1994; 267: L250-L255. 
22. Agustí C, Takeyama K, Cardell LO, et al. Goblet cell degranulation after antigen challenge in sensitized guinea pigs: Role of neutrophils. Am J Respir Crit Care Med 1998; 158: 1253-1258.

23. Jorens PG, Richman-Eisenstat JB, Housset BP, et al. Interleukin-8 induces neutrophil accumulation but not protease secretion in the canine trachea. Am J Physiol 1992; 263 (Lung Cell Mol Physiol 7) L708-713.

24. Owen CA, Campbell MA, Boukedes SS, Campbell EJ. Cytokines regulate membrane-bound leukocyte elastase on neutrophils: a novel mechanism for effector activity. Am J Physiol 1997; 272 (Lung Cell Mol Physiol 16) L385-393.

25. Owen CA, Campbell MA, Sannes PL, Boukedes SS, Campbell EJ. Cell surface-bound elastase and cathepsin G on human neutrophils: a novel, non-oxidative mechanism by which neutrophils focus and preserve catalytic activity of serine proteinases. J Cell Biol 1995; 131: 775-789.

26. Rao NV, Marshall BC, Gray BH, Hoidal JR. Interaction of secretory leukocyte protease inhibitor with proteinase3. Am J Respir Cell Mol Biol 1993; 8: 612-616.

27. Renesto P, Balloy V, Kamimura T, Masuda K, Imaizumi A, Chignard M. Inhibition by recombinant SLPI and halfSLPI (Asn55-Ala107) of elastase and cathepsin G activities: consequence for neutrophil-platelet cooperation. Br J Pharmacol 1993; 108: 1100-1106.

28. Sommerhoff CP, Krell RD, Williams JL, Gomes BC, Strimpler AM, Nadel JA. Inhibition of human neutrophil elastase by ICI 200,355. Eur J Pharmacol 1991; 193 : 153-158.

29. Sallenave JM, Si-Tahar M, Cox G, Chignard M, Gauldie J. Secretory leukocyte proteinase inhibitor is a major leukocyte elastase inhibitor in human neutrophils. J Leukoc Biol 1997; 61: 695-702.

30. Piedboeuf B, Frenette J, Petrov P, Welty, SE, Kazzaz JA, Horowitz S. In vivo expression of intercellular adhesion molecule 1 in type II pneumocytes during hyperoxia. $\mathrm{Am}$ J Respir Cell Mol Biol 1996; 15: 71-77.

31. Sommerhoff CP, Krell RD, Williams JL, Gomes BC, Strimpler AM, Nadel JA. Mast cell chymase. A potent secretagogue for airway gland serous cells. J Immunol 1989; 142: 2450-2456.

32. Sommerhoff CP, Fang KC, Nadel JA, Caughey GH. Classical second messengers are not involved in proteinase-induced degranulation of airway gland cells. Am JPhysiol 1996; 271 (Lung Cell Mol Physiol 15): L796-L803.

33. Choi AMK, Jacoby DB. Influenza virus A infection induces interleukin-8 gene expression in human airway epithelial cells. FEBS 1992; 309: 327-329.

34. Henderson WR Jr, Lewis DB, Albert RK, et al. The importance of leukotrienes in airway inflammation in a mouse model of asthma. J Exp Med 1996; 184: 14831494.

35. Gold WM. Pulmonary function testing. In: Murray JF, Nadel JA, eds. Textbook of Respiratory Medicine. Philadelphia, PA, Saunders, 1994; pp. 798-900. 